\title{
Effect of REM Addition on The Surface Tension and The Critical Temperature of The Immiscible Liquid Phase Separation of The $60 \% \mathrm{Bi}-24 \% \mathrm{Cu}-16 \% \mathrm{Sn}$ alloy
}

\author{
Joongchul Park, Soonki Min and Joonho Lee ${ }^{{ }^{\dagger}}$ \\ *Department of Materials Science and Engineering, Korea University, 5 Anam-dong, Seongbuk-gu, \\ Seoul 136-713, Korea
}

(Received November 26, 2008 : Received in reviced form December 16, 2008 : Accepted December 18, 2008)

\begin{abstract}
For the fabrication of core-shell structure bimetallic lead-free solder balls, both the critical temperature $\left(\mathrm{T}_{\mathrm{cr}}\right)$ for the phase separation of two immiscible liquid phases and the temperature coefficient of the interfacial tension between the two separated liquid phases are required. In order to obtain this information, the temperature dependence of the surface tension of $60 \% \mathrm{Bi}-24 \% \mathrm{Cu}-16 \% \mathrm{Sn}(-\mathrm{REM})$ alloys was measured using the constrained drop method. The slope of the temperature dependence of the surface tension changed clearly at a critical temperature for the separation of two immiscible liquid phases. The critical temperature of the $60 \% \mathrm{Bi}-24 \% \mathrm{Cu}-16 \% \mathrm{Sn}$ alloy was estimated to be $1097 \mathrm{~K}$. An addition of $0.05 \%$ Ce decreased the critical temperature to $1085 \mathrm{~K}$, whereas that of $0.05 \%$ La increased it to $1117 \mathrm{~K}$. It was found that the surface tension and its temperature coefficient of the $60 \% \mathrm{Bi}-24 \% \mathrm{Cu}-16 \% \mathrm{Sn}$ alloy were slightly increased by the addition of $0.05 \% \mathrm{Ce}$ and $0.05 \% \mathrm{La}$. In addition, additions of $\mathrm{Ce}$ and La increased the temperature coefficient of the interfacial tension.
\end{abstract}

Key words characterization method, critical temperature, rare earth metal, solder, surfaces, surface tension.

\section{Introduction}

As a potential candidate of the next-generation leadfree solder balls, the core-shell structure bimetallic lead-free solder ball was suggested by Wang et al. in 2002. ${ }^{1)}$ This new bimetallic solder ball is composed of two phases: surface phase (lower surface tension and larger volume fraction) and core phase (higher surface tension and smaller volume fraction). When the gas atomizer method is applied to the fabrication of the solder balls, the surface tension of this alloy is one of the most important factors to be measured. ${ }^{2)}$ In the course of cooling of fine particles, the phase separation occurs due to the liquid phase immiscibility. Once the phase separation occurs in a liquid drop, the phase of lower surface tension moves to the outside, and that of higher surface tension moves to the center. Driving force for the movements of two immiscible phases is the interfacial tension gradients along with the temperature difference. Accordingly, the surface tension and the interfacial

Corresponding author

E-Mail : joonholee@korea.ac.kr (J. Lee) tension between two immiscible liquid alloys are required to control of the core-shell structure. ${ }^{1)}$ Wang et al. suggested $60 \% \mathrm{Bi}-24 \% \mathrm{Cu}-16 \% \mathrm{Sn}$ (in $\mathrm{wt} \%$ ) as the first candidate alloy. 1 )

On the other hand, there are several reports on the roles of rare earth metals on the improvements in soldering properties of lead-free solder alloys. For example, Wang et al. reported that the wetting property of $\mathrm{Sn}-3.5 \% \mathrm{Ag}$ solder alloy was improved by addition of $0.25 \sim 0.5 \%$ La and Ce. ${ }^{3)}$ They also reported that the mechanical properties (ultimate strength, ductility) were slightly improved by the addition of $0.5 \% \mathrm{La}$ and Ce. Recently, Wang et al. investigated the effect of the addition of $\mathrm{Ce}$ on the solderability of $\mathrm{Sn}-\mathrm{Ag}$ $\mathrm{Cu}$ and $\mathrm{Sn}-\mathrm{Ag}-\mathrm{Ni}$ solder alloys on $\mathrm{Cu}$ substrates. ${ }^{4)}$ They found that the solderability was improved by adding small amount of $\mathrm{Ce}(0.03 \sim 0.05 \%)$. They also reported that the mechanical properties of soldered joints were enhanced with the addition of Ce. In their investigation, Ce segregated at grain boundaries and increased the resistance of grain growth to make a fine structure. However, the effects of these REM on the surface property and the critical temperature for a system having a miscibility gap have not been studied 
yet as the authors' knowledge.

Recently, we have suggested a new method to determine the critical temperature of immiscible liquid phase separation from the temperature dependence of the surface tension of the $60 \% \mathrm{Bi}-24 \% \mathrm{Cu}-16 \% \mathrm{Sn}$ alloy. In this paper, the effects of REM addition $(0.05 \% \mathrm{Ce}$ and $0.05 \% \mathrm{La}$ ) on the surface tension and the critical temperature of the $60 \% \mathrm{Bi}-24 \% \mathrm{Cu}-16 \% \mathrm{Sn}$ alloy were investigated. In addition, using the critical temperature, the interfacial tensions between two immiscible liquid alloys were estimated.

\section{Experimental procedure}

Experimental details were reported in our previous papers. ${ }^{5,6)}$ In the present experiments, metals of high purity (Bi: 99.999\%, Sn: 99.999\%, Cu: 99.999\%, La: 99.9\%, and Ce: $99.9 \%$ ) were used for the alloy preparation. Approximately $2.7 \mathrm{~g}$ alloy sample was prepared by melting them with an induction furnace under a purified Ar gas atmosphere. During the preparation of the alloys, the alumina crucible containing metals was covered by a graphite cap to suppress the evaporation of component metals. In addition, in order to prevent the oxidation of the sample metals by the trace of oxygen in the gas, sponge titanium granules were placed on the top surface of the graphite cap. In Fig. 1, a schematic diagram of the experimental apparatus is shown. The sample alloy melted in the upper graphite crucible with a hole at the bottom was dropped in a graphite crucible constraining

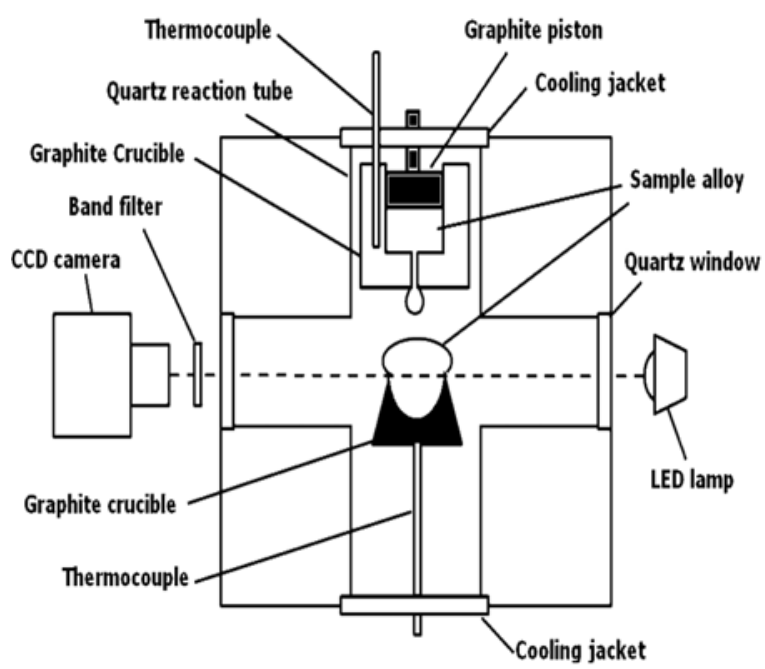

Fig. 1. A schematic diagram of the experimental apparatus.' an axi-symmetric liquid alloy drop at $1163 \mathrm{~K}$. The image of this drop was captured with a high resolution CCD camera, which image was used in the calculation of the surface tension. In order to measure the temperature dependence of the surface tension, the measurements were carried out at every 10 or $20 \mathrm{~K}$ by decreasing temperature to $1003 \mathrm{~K}$.

\section{Results and discussion}

The temperature dependence of the surface tension of the $60 \% \mathrm{Bi}-24 \% \mathrm{Cu}-16 \% \mathrm{Sn}$ alloy is shown in Fig. $2^{5)}$ It is clearly found that the temperature dependence of the surface tension clearly changed from $1097 \mathrm{~K}$, which temperature is considered as the critical temperature for the immiscible phase separation. Below the critical temperature the homogeneous liquid phase is separated to two immiscible liquid phases (Bi-rich phase and ( $\mathrm{Cu}, \mathrm{Sn})$-rich phase). The ( $\mathrm{Cu}, \mathrm{Sn})$-rich phase (higher surface tension) is located on the upper region because it is lighter than the Bi-rich phase (lower surface tension). Accordingly, the apparent surface tension suddenly increases as found in Fig. 2.

In Fig. 3, the surface tensions of Bi-Sn-Cu$0.05 \% \mathrm{La}$ and $\mathrm{Bi}-\mathrm{Sn}-\mathrm{Cu}-0.05 \% \mathrm{Ce}$ alloys are shown. For these two alloys, the critical temperatures could be obtained from the change in the temperature dependence of the surface tension either. The temperature dependence of the surface tension of the homogeneous alloys above the critical temperature was increased by adding $\mathrm{Ce}$ and $\mathrm{La}$. In addition, by the addition of $0.05 \%$ of $\mathrm{Ce}$, the critical temperature was decreased to $1085 \mathrm{~K}$, whereas the addition of

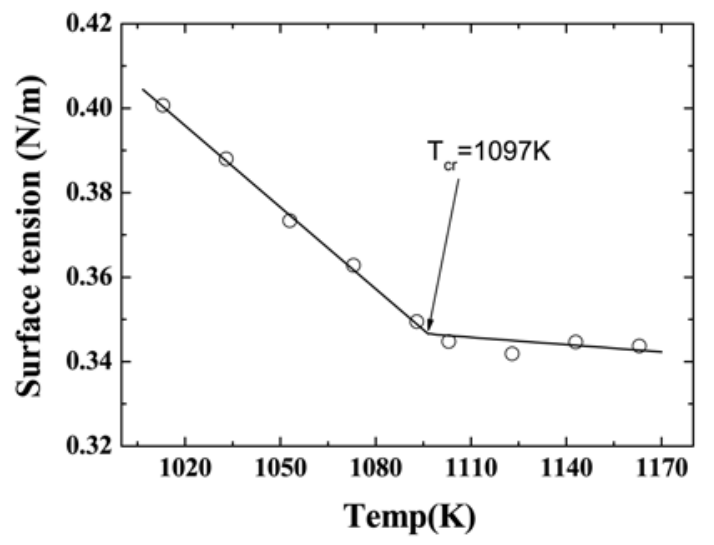

Fig. 2. The surface tension of the $60 \% \mathrm{Bi}-24 \% \mathrm{Cu}-16 \% \mathrm{Sn}$ alloy as a function of the temperature. ${ }^{5)}$ 


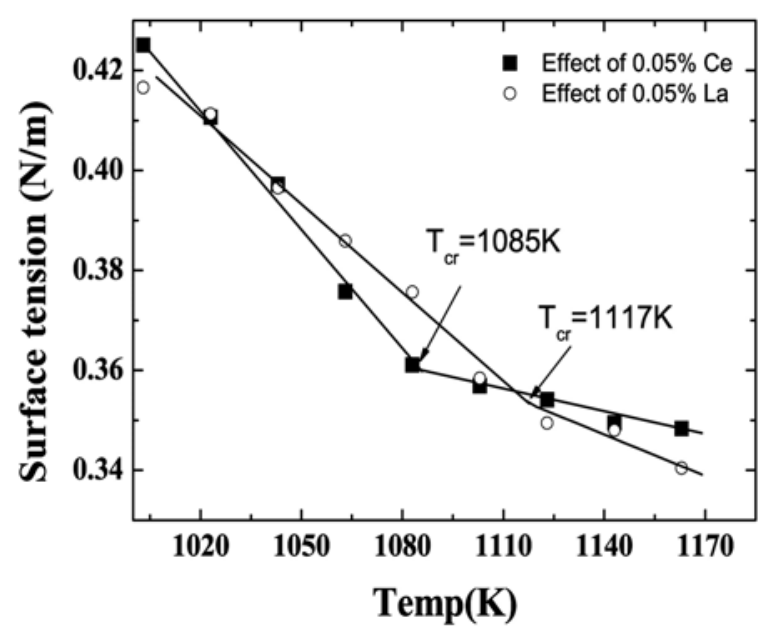

Fig. 3. Effect of the addition of $0.05 \% \mathrm{La}$ and $0.05 \% \mathrm{Ce}$ on the surface tension of the $60 \% \mathrm{Bi}-24 \% \mathrm{Cu}-16 \% \mathrm{Sn}$ alloy and the critical temperature.

$0.05 \%$ of $\mathrm{La}$ increased the critical temperature up to $1117 \mathrm{~K}$. If a regular solution model is assumed, the interaction energy is proportional to the critical temperature. Consequently, it was considered that the addition of $\mathrm{Ce}$ decreased, whereas that of $\mathrm{La}$ increased the interaction energy of the liquid phase.

The core-shell structure formation can be enhanced by the Marangoni convection during the cooling process (Fig. 4) ${ }^{1)}$ As the temperature gradient from the center to the surface of the liquid drop increases, the velocity of a liquid drop $\left(V_{m}\right)$ in a liquid matrix would increase according to Eq.(1). ${ }^{1)}$

$$
V_{m} \approx \frac{-2 \mathrm{r}}{3\left(3 \mu_{d}+2 \mu_{m}\right)} \cdot\left(\frac{\delta \sigma}{\delta T}\right) \cdot\left(\frac{\delta T}{\delta x}\right)
$$

where $r$ is the radius of the liquid drop, $\mu_{d}$ is the viscosity of the liquid drop, $\mu_{m}$ is the viscosity of the liquid matrix, $\sigma$ is the interfacial tension, $\mathrm{T}$ is the temperature, $x$ is the distance. Consequently, the higher the interfacial tension gradients, the formation of the core-shell structure would be enhanced. There are not so many experimental or theoretical researches on the interfacial tension between two immiscible liquid alloys. Recently, Kaptay ${ }^{7}$ suggested a semiempirical equation to predict the interfacial tension between two immiscible liquids based on the models of Chatain et al. $^{8)}$ and Hoyer et al. ${ }^{9)}$ Simply, the interfacial tension $(\sigma)$ can be expressed by Eq. (2).

$$
\sigma=\frac{6.05 T_{c r}+7 T}{1.06 \cdot\left(N_{A v}\right)^{1 / 3}\left(\sum_{i} X_{i} V_{i}\right)^{2 / 3}} \times\left[1-\frac{T}{T_{c r}}\right]^{1.26}
$$

where $N_{A V}$ is the Avogadro's number, $X_{i}$ is the mole fraction of the component $i, V_{i}$ is the molar volume of the component $i$, and $T$ is the temperature in $\mathrm{K}$, respectively. This equation successfully described the interfacial tension of the $\mathrm{Ga}-\mathrm{Pb}$ and $\mathrm{Al}-\mathrm{Bi}$ systems. ${ }^{7}$ According to the thermodynamic calculation, the $60 \% \mathrm{Bi}-24 \% \mathrm{Cu}-16 \% \mathrm{Sn}$ system can be treated as a pseudo-binary system of $\mathrm{Sn}_{0.247} \mathrm{Cu}_{0.753}-\mathrm{Sn}_{0.069} \mathrm{Bi}_{0.931}$. If we assume that eq. (2) is valid for such a pseudobinary system, the interfacial tension and its temperature dependence can be calculated. In Fig. 5, the

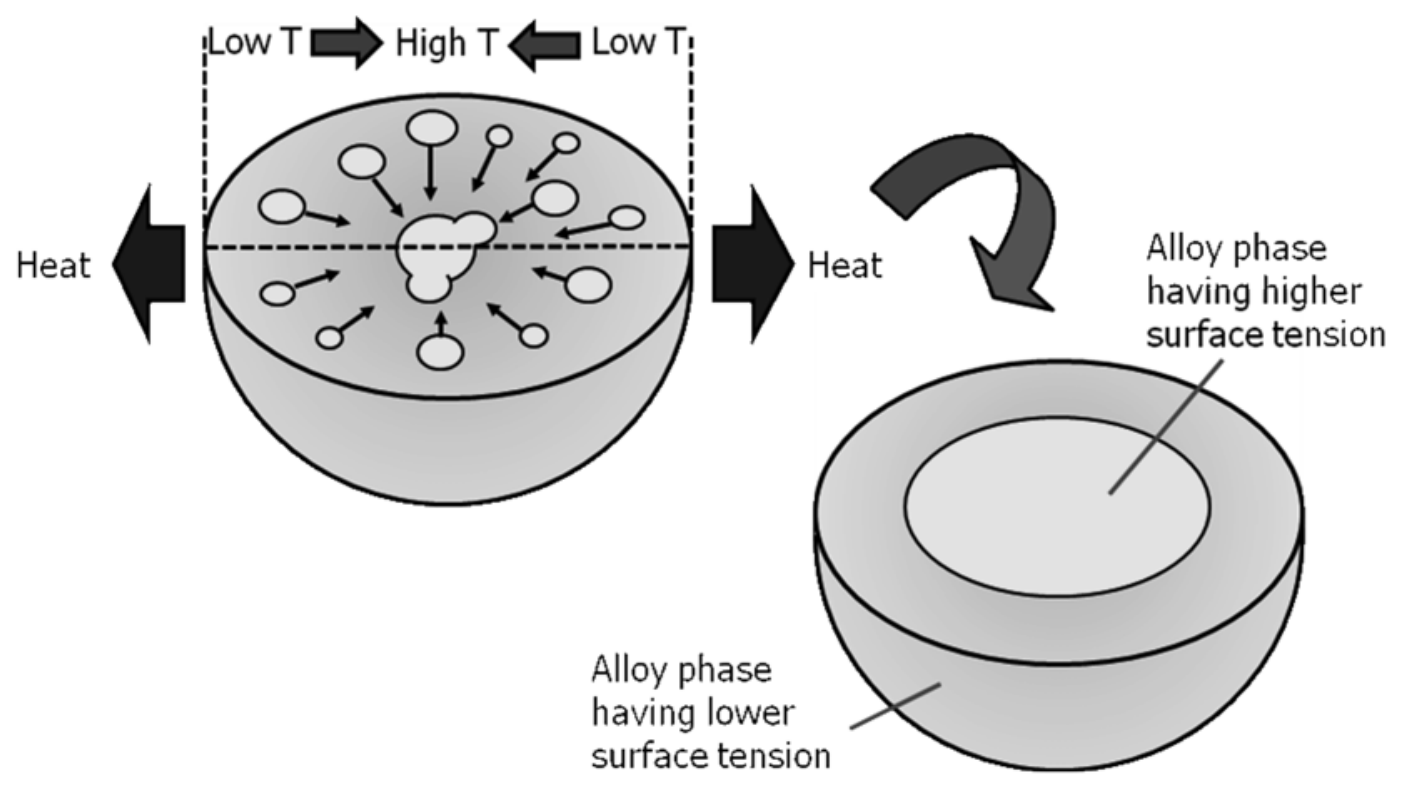

Fig. 4. A schematic illustration of the core-shell structure formation mechanism due to Marangoni convection. ${ }^{1)}$ 


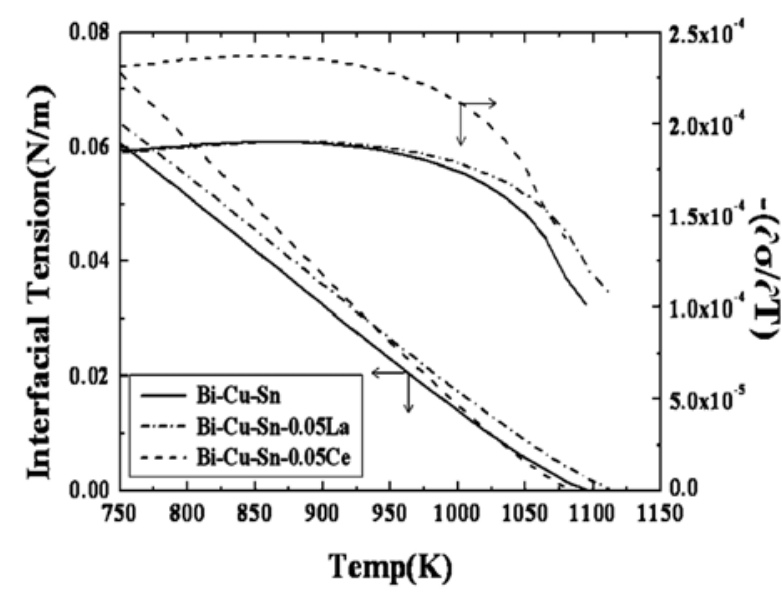

Fig. 5. The interfacial tension and the temperature dependence $(\delta \sigma / \delta T)$ of the $60 \% \mathrm{Bi}-24 \% \mathrm{Cu}-16 \% \mathrm{Sn}-(\mathrm{REM})$ alloys (calculated using Eq. (2)).

calculated interfacial tension and the temperature dependence for the tested three alloys are shown. Molar volumes of pure metals were taken from ref.10) and the critical temperature obtained in the present study was applied in the calculations. It is found that the additions of $\mathrm{Ce}$ and $\mathrm{La}$ increase the temperature coefficient of the interfacial tension. Especially, the effect of $\mathrm{Ce}$ is much remarkable. If the assumption made here is valid, it is expected that the addition of $\mathrm{Ce}$ would enhance the core-shell structure formation.

\section{Conclusions}

In this study, the effect of $0.05 \% \quad \mathrm{Ce}$ and $0.05 \%$ $\mathrm{La}$ additions on the surface tension and its temperature dependence of the $60 \% \mathrm{Bi}-24 \% \mathrm{Cu}-16 \% \mathrm{Sn}$ alloy were investigated using the constrained drop method.
It was found that the surface tension and its temperature coefficient of the $60 \% \mathrm{Bi}-24 \% \mathrm{Cu}-16 \% \mathrm{Sn}$ alloy were slightly increased by the addition of $0.05 \% \mathrm{Ce}$ and $0.05 \%$ La. In addition, from the temperature dependence of the surface tension, the critical temperature could be obtained. The addition of $\mathrm{Ce}$ decreased the critical temperature, whereas that of La increased.

\section{Acknowledgement}

This project was supported by Korea Science and Engineering Foundation through the joint research program (Grant number: F01-2007-000-10072-0). SM and JP are supported by Brain Korea 21 Program. We are also very grateful to Prof. G. Kaptay for his kind discussion.

\section{References}

1. C. P. Wang, X. J. Liu, I. Ohnuma, R. Kainuma and K. Ishida, Science, 297, 990 (2002).

2. R. M. German, Powder Metallurgy Science, 2nd ed., p.112, Metal Powder Industries Federation, New Jersey, 1994.

3. L. Wang, D. Q. Yu, J. Zhao and M. L. Huang, Mater. Lett., 56, 1039 (2002).

4. J. X. Wang, S. B. Xue, Z. J. Han, S. L. Yu and Y. Chen, Y. P. Shi, H. Wang, J. Alloys Compd., 467, 219 (2009).

5. S. Min, J. Park and J. Lee, Mater. Lett., 62, 4464 (2008).

6. T. Tanaka, M. Nakamoto, R. Oguni, J. Lee and S. Hara, Z. Metallkd., 95, 818 (2004).

7. G. Kaptay, Calphad, 32, 338 (2008).

8. D. Chatain, N. Eustathopoulos and P. Desre, J. Coll. Interface Sci., 81, 384 (1981).

9. W. Hoyer, I. Kaban and M. Merkwitz, J. Opt. Adv. Mater., 5, 1069 (2003).

10. T. Iida, R. I. L. Guthrie, The physical properties of liquid metals, p.71-72, Clarendon press, Oxford, 1993. 